\title{
Prevalence, risk factors and outcome of congenital anomalies among neonatal admissions in OGBOMOSO, Nigeria
}

\author{
Akinlabi E. Ajao ${ }^{1,2^{*}}$ (D) and Ikeola A. Adeoye
}

\begin{abstract}
Background: Congenital anomalies (CA) are a major cause of neonatal morbidity and mortality, especially in developing countries. Data on these anomalies are still poorly collated in developing countries. We aimed to assess the prevalence, pattern, risk factors and outcome of congenital anomalies among neonatal admissions in Ogbomoso Town, Nigeria.

Methods: A cross-sectional retrospective study in which a review of the records of all neonates admitted in the neonatal unit of the Bowen University Teaching Hospital, Ogbomoso over a five-year period (January 2012December 2016) was undertaken. The occurrence rate and pattern of anomalies were determined, while factors associated with the occurrence and outcome of anomalies were calculated with the odds ratio and 95\% confidence interval. Data entry and analysis were performed using SPSS version 21.
\end{abstract}

Results: CA were found in 67 of the 1057 neonatal admissions, giving a prevalence rate of $6.3 \%$. Anomalies of the cardiovascular and digestive systems were the most common. A higher proportion of babies referred from other facilities had CA, and this was found statistically significant. There was no significant association between CA and low birth weight, sex, maternal age or parity. The mortality rate among neonates with CA was $10.4 \%$. Although, CA was associated with reduced risk of neonatal mortality compared to those with other acute conditions, this was not statistically significantly.

Conclusion: CA is a major indication for neonatal admissions in Ogbomoso. There is the need to establish a surveillance system for CA and efforts should be made to raise awareness of the occurrence and risk factors of CA in developing countries.

Keywords: Congenital anomalies, Neonates, Prevalence, Risk factors, Outcome, Developing countries

\section{Background}

Congenital anomalies (CA), or birth defects, are structural, behavioural, functional and metabolic disorders that occur during intrauterine life and can be identified prenatally, at birth or later in infancy [1,2]. While birth asphyxia, prematurity and infections are the leading causes of adverse neonatal outcomes, congenital anomalies contribute significantly to neonatal morbidity and mortality. An estimated 7.9 million children are born with major congenital anomalies every year [3]. The

\footnotetext{
* Correspondence: akinlabi.ajao@gmail.com

'Department of Epidemiology and Medical Statistics, University of Ibadan, Ibadan, Nigeria

${ }^{2}$ Department of Surgery, Bowen University, Iwo, Nigeria
}

proportion of global neonatal mortality due to these defects increased from 3\% in 2008 to $4.4 \%$ in 2013 [4, 5]. Unfortunately, more than $90 \%$ of congenital anomalies occur in low and middle income countries (LMICs) [6].

Major CAs are defined as anomalies with significant effect on life expectancy and they occur in $2-3 \%$ of live births and in $20-30 \%$ of still births [1, 7]. Their prevalence, however, varies with time and geographical location reflecting a complex interaction between genetics and environmental factors [8]. They account for about $3 \%$ of live births and $15-30 \%$ of paediatric hospitalizations in the United States [7, 9]. In Sub-Saharan Africa, Ndibazza et al. reported a prevalence of more than $7 \%$ in Entebbe,

(C) The Author(s). 2019 Open Access This article is distributed under the terms of the Creative Commons Attribution 4.0 International License (http://creativecommons.org/licenses/by/4.0/), which permits unrestricted use, distribution, and reproduction in any medium, provided you give appropriate credit to the original author(s) and the source, provide a link to the Creative Commons license, and indicate if changes were made. The Creative Commons Public Domain Dedication waiver (http://creativecommons.org/publicdomain/zero/1.0/) applies to the data made available in this article, unless otherwise stated. 
Uganda and hospital-based studies from Nigeria have shown prevalence ranging between 0.4 and $11.1 \%$ [10-13].

All organ systems within the body can be affected by CA. The musculoskeletal system is the most often affected system in studies that have focused on externally visible anomalies $[3,8,10,14,15]$. In other studies, the cardiovascular and gastrointestinal systems have predominated [9, 16-18]. In previous studies from Nigeria, the gastrointestinal system has been the most reported [13, 19, 20].

Understanding the aetiology of CA is important in prevention and in genetic counselling that may help in eradication. Generally, the aetiology of birth defects remains unclear but is thought to be multifactorial. These factors may be genetic (10-30\%), environmental (5$10 \%)$ or due to multifactorial inheritance (20-35\%), while $30-45 \%$ are unknown [7]. Infectious agents appear to be the most important environmental factor in LMICs [6]. Implicated maternal factors include age, lifestyle, illnesses during pregnancy, antenatal care, medication use and non-use of peri-conceptual folic acid [1, 7, 14, 17, 21]. Parental consanguinity, previous miscarriages and stillbirths, and inheritable congenital disease are other important factors in the aetiology of CAs [14, 17, 21].

Mortality is very high among major CA in LMICs rising to $20-85 \%$ (as against less than 10\% in high-income countries) and generally, mortality is higher among infants with CA compared to normal births [6, 22-24]. Ninety-five per cent of deaths among children with CA worldwide occur in LMICs [22]. A significant number of survivors also suffer life-long disabilities, with birth defects accounting for 25.3 to 35.8 million disability-adjusted life years, worldwide $[3,6]$.

Despite the huge burden of congenital anomalies in LMICs, there is still a dearth of comprehensive data on these conditions as birth defects registries are absent [3]. There is significant under-estimation of CA in LMICs due to non-presentation at health facilities, under-reporting, deficient diagnostic capacity and poor awareness $[3,25]$. Prevalence studies are needed to establish baseline rates, demonstrate changes that occur over time and give clues to aetiology [11]. This study assessed perinatal and maternal factors that may be associated with the occurrence of these congenital anomalies. Outcomes of neonatal admissions with congenital anomalies were compared with other neonatal admissions with other acute conditions to assess their relative morbidity and mortality. This study may, therefore, guide policy makers to increase surveillance of these conditions and perhaps raise awareness of the impact of these anomalies within overall neonatal mortality.

We aimed to assess the prevalence, pattern, risk factors and outcome of congenital anomalies among neonatal admissions in a Tertiary Hospital in a semi-urban area, South-West, Nigeria.

\section{Methods}

\section{Study setting}

This study was conducted at the Neonatal Unit of the Bowen University Teaching Hospital (BUTH), Ogbomoso. BUTH is a faith-based tertiary institution, which is located in semi-urban Ogbomoso, in Oyo State, South-West Nigeria. The institution provides multi-specialist care and serves as a major referral center for hospitals within and outside Ogbomoso, including towns in three states. The hospital was initially established as a general hospital in 1907 but was upgraded to a teaching hospital in 2009. The neonatal unit provides care for neonates delivered within and outside the hospital. However, babies requiring ventilator support and other intensive care are referred elsewhere.

\section{Study design}

This was a cross-sectional study, conducted by retrospectively reviewing the medical records of all neonates admitted at the neonatal unit of BUTH over a five-year period between January 2012 and December 2016. Ethical approval for the study was obtained from the institutional research ethics committee. For the purpose of this study, congenital anomalies were defined as structural defects that were present at birth or identified during the neonatal period, either clinically or through investigation modalities. Categorization of these anomalies was then done using the European Surveillance of Congenital Anomalies (EUROCAT) guidelines [26]. Perinatal asphyxia was defined as failure to establish breathing at birth (using the WHO definition) and an APGAR score of less than 7 after 5 min of birth, while those with APGAR score of 3 or less at this time were classified as having severe perinatal asphyxia. Preterm births were defined as deliveries occurring before the completion of 37-week gestation. Obstetric complications were defined as adverse maternal events that are related to pregnancy, such as antepartum haemorrhage and pregnancy induced hypertensive disorders.

Data were collected on neonatal, birth and maternal characteristics, congenital anomaly status and the outcome of the admission were obtained. Information on neonatal characteristics obtained included: sex, age at presentation, gestational age at birth, birth weight, and type of gestation, place of birth and mode of delivery. Maternal factors obtained were age, parity, antenatal care, folic acid use, febrile illness during pregnancy, self-medication and lifestyle variables, such as smoking and alcohol intake during pregnancy. The outcome variables were the status at discharge (discharged, referred, discharged against medical advice and died); and the mortality experience.

\section{Statistical analysis}

Data collected were analyzed using the SPSS version 21 . Categorical variables were summarized using frequencies, 
ratios and proportions, along with the 95\% confidence interval. Continuous variables were summarized using mean, standard deviation, or median and interquartile range (IQR). The prevalence rate of CA was calculated as the proportion of neonates with CA among the total number of neonates admitted during the study period. Associations of neonatal characteristics and maternal socio-demographic factors with congenital anomalies were tested using the chi square statistic. Risk factors were assessed using the binary logistic regression, and the odds ratio and 95\% confidence intervals were reported. Bivariate Cox regression analysis was used to assess variables that were significantly associated with neonatal mortality at $p<0.2$, and significant variables were included in a multivariate Cox regression analysis to determine the predictors of 28-day mortality among neonatal admissions at $p<0.05$. The level of significance was set at $p<0.05$.

\section{Results}

Figure 1 shows the distribution of all neonates admitted based on the disease condition. Sixty-seven (67) of the 1057 admitted neonates had CA during this five-year period giving an overall prevalence rate of $6.3 \%$. The median age at presentation was 2 days (IQR, 6 days) and 36 $(53.7 \%)$ were males. The mean birth weight was $2.5( \pm$ $0.7) \mathrm{kg}$, and $58.3 \%$ of these neonates had birth weights of $2.5 \mathrm{~kg}$ and above. Seventy-five percent of these neonates were delivered via the vaginal route and $38 \%$ were delivered preterm (Table 1). Twenty-three patients (34.3\%) had associated perinatal asphyxia. The mean maternal age of neonates with congenital anomalies was $29.8( \pm 5.4)$ years. A higher proportion of patients referred from peripheral facilities had CA (8.9\%) compared to $3.9 \%$ of those delivered within the study location, and this difference was statistically significant $(p<0.05)$. The

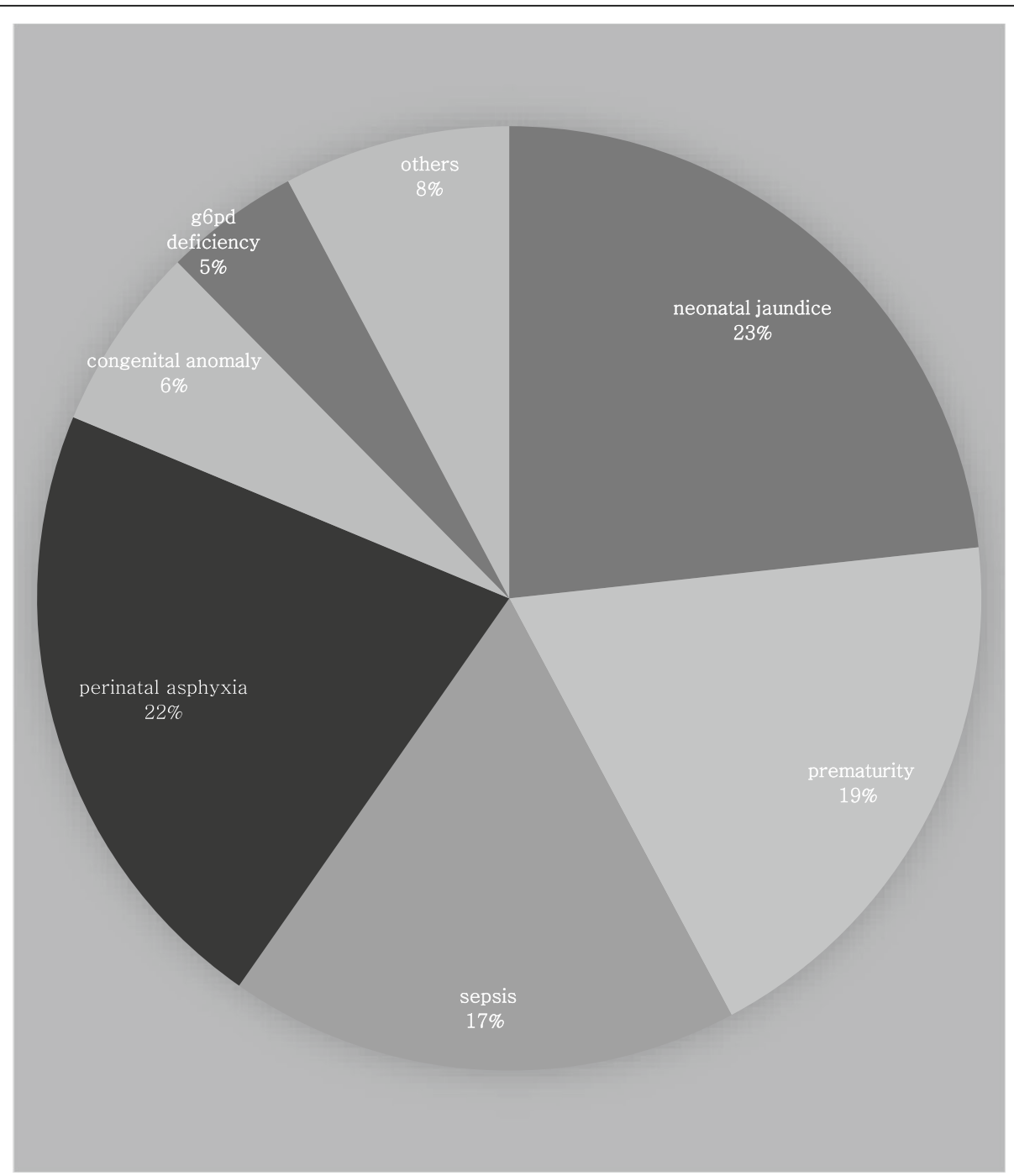

Fig. 1 Pie chart illustrating the distribution of neonatal admissions in BUTH between 2012 and 2016 
Table 1 Neonatal \& maternal socio-demographic factors of study population by congenital anomaly status

\begin{tabular}{|c|c|c|c|c|}
\hline \multirow[t]{2}{*}{ Characteristic } & \multicolumn{4}{|c|}{ Congenital anomaly } \\
\hline & Yes $n(\%)$ & No $n(\%)$ & Total $n(\%)$ a & $p$ value \\
\hline \multicolumn{5}{|l|}{ Sex } \\
\hline Male & $36(5.9)$ & $576(94.1)$ & $612(57.9)$ & \multirow[t]{3}{*}{0.475} \\
\hline Female & $31(7.0)$ & $414(93.0)$ & $445(42.1)$ & \\
\hline Total & $67(6.3)$ & $990(93.7)$ & $1057(100.0)$ & \\
\hline \multicolumn{5}{|c|}{ Age at presentation } \\
\hline 0-7 days & $59(6.4)$ & 870 (93.6) & $929(87.9)$ & \multirow[t]{3}{*}{0.930} \\
\hline 8-28 days & $8(6.6)$ & $114(93.4)$ & $122(11.5)$ & \\
\hline Missing ${ }^{b}$ & $0(0.0)$ & $6(100.0)$ & $6(0.6)$ & \\
\hline \multicolumn{5}{|c|}{ Gestational age at birth } \\
\hline Preterm & $13(5.1)$ & $241(94.9)$ & $254(24.0)$ & \multirow[t]{3}{*}{0.477} \\
\hline Term & $21(4.0)$ & $503(96.0)$ & $524(49.6)$ & \\
\hline Missing ${ }^{b}$ & $33(11.8)$ & $246(88.2)$ & $279(26.4)$ & \\
\hline \multicolumn{5}{|l|}{ Mode of delivery } \\
\hline Vaginal & $50(7.1)$ & $659(92.9)$ & $709(67.1)$ & \multirow[t]{3}{*}{0.228} \\
\hline Abdominal & $17(5.1)$ & $317(94.9)$ & $334(31.6)$ & \\
\hline Missing ${ }^{b}$ & $0(0.0)$ & $14(100.0)$ & $14(1.3)$ & \\
\hline \multicolumn{5}{|l|}{ Place of birth } \\
\hline Within BUTH & $20(3.9)$ & $494(96.1)$ & $514(48.6)$ & \multirow[t]{3}{*}{$0.001^{*}$} \\
\hline Referred & $46(8.9)$ & $473(91.1)$ & $519(49.1)$ & \\
\hline Missing ${ }^{b}$ & $1(4.2)$ & $23(95.8)$ & $24(2.3)$ & \\
\hline \multicolumn{5}{|c|}{ Obstetric complication } \\
\hline Yes & $13(5.4)$ & $227(94.6)$ & $240(22.7)$ & \multirow[t]{3}{*}{0.518} \\
\hline No & $52(6.6)$ & $739(93.4)$ & $791(74.8)$ & \\
\hline Missing ${ }^{b}$ & $2(7.7)$ & $24(92.3)$ & $26(2.5)$ & \\
\hline \multicolumn{5}{|l|}{ Birth weight (kg) } \\
\hline$<1.5$ & $5(4.8)$ & $100(95.2)$ & $105(10.0)$ & \multirow[t]{4}{*}{0.420} \\
\hline $1.5-2.49$ & $20(8.5)$ & $216(91.5)$ & $236(22.3)$ & \\
\hline$\geq 2.5$ & $35(6.6)$ & $495(93.4)$ & $530(50.1)$ & \\
\hline Missing ${ }^{b}$ & $7(3.8)$ & $179(96.2)$ & $186(17.6)$ & \\
\hline \multicolumn{5}{|c|}{ Perinatal asphyxia } \\
\hline Yes & $23(7.1)$ & $302(92.9)$ & $325(30.7)$ & \multirow[t]{3}{*}{0.514} \\
\hline No & $42(6.0)$ & $657(94.0)$ & $699(66.2)$ & \\
\hline Missing $^{b}$ & $2(6.1)$ & $31(93.9)$ & $33(3.1)$ & \\
\hline \multicolumn{5}{|c|}{ Maternal age (years) } \\
\hline$\leq 20$ & $4(12.1)$ & $29(87.9)$ & $33(3.1)$ & \multirow[t]{4}{*}{0.393} \\
\hline $21-35$ & $31(7.2)$ & $399(92.8)$ & $430(40.7)$ & \\
\hline$>35$ & $4(4.9)$ & $78(95.1)$ & $82(7.8)$ & \\
\hline Missing $^{b}$ & $28(5.5)$ & $484(94.5)$ & $512(48.4)$ & \\
\hline \multicolumn{5}{|l|}{ Maternal tribe } \\
\hline Yoruba & $60(6.3)$ & $895(93.7)$ & $955(90.4)$ & \multirow[t]{3}{*}{0.678} \\
\hline Igbo & $3(9.7)$ & $28(90.3)$ & $31(2.9)$ & \\
\hline Others & $1(4.2)$ & $23(95.8)$ & $24(2.3)$ & \\
\hline
\end{tabular}

Table 1 Neonatal \& maternal socio-demographic factors of study population by congenital anomaly status (Continued)

\begin{tabular}{|c|c|c|c|c|}
\hline \multirow[t]{2}{*}{ Characteristic } & \multicolumn{4}{|c|}{ Congenital anomaly } \\
\hline & Yes $n(\%)$ & No $n(\%)$ & Total $n(\%)$ a & $p$ value \\
\hline Missing $^{b}$ & $3(6.4)$ & 44 (93.6) & $47(4.4)$ & \\
\hline \multicolumn{5}{|c|}{ Maternal place of domicile } \\
\hline Ogbomoso & $48(5.9)$ & $763(94.1)$ & $811(76.7)$ & 0.240 \\
\hline Outside Ogbomoso & $16(8.2)$ & $179(91.8)$ & $195(18.5)$ & \\
\hline Missing ${ }^{b}$ & $3(5.9)$ & $48(94.1)$ & $51(4.8)$ & \\
\hline
\end{tabular}

${ }^{a}$ Column percentage; ${ }^{b}$ Missing data excluded from analysis; *Statistically significant

mothers were mainly of the Yoruba ethnic group (89.6\%) and $71.6 \%$ were domiciled within the town of study.

Anomalies of the cardiovascular system were the commonest anomalies in this cohort, occurring in $14(20.9 \%)$ of the neonates with CAs (Table 2). Three of the neonates with cardiovascular CAs had multiple anomalies and the predominant defect was ventricular septal defect observed in six neonates. This was followed by anomalies of the digestive system occurring in 12 (17.9\%), with anorectal malformations being the predominant anomaly affecting four of the neonates. Fifty-three (79.1\%) of the anomalies occurred in isolation, while 14 (20.9\%) were syndromic.

Glucose-6-phosphate dehydrogenase (G6PD) deficiency, a metabolic CA, occurred in 50 (4.7\%) of the patients. Diagnosis of this condition was established using a qualitative screening test. No quantitative assay had been done on these patients. These neonates were, however, not included in analysis of CAs as the study focused on only structural anomalies.

The practice of self-medication and the use of herbal preparations during pregnancy were associated with higher risks of CAs but this was not statistically significant $(p>0.05)$ (Table 3). Young mothers aged 20 years and less were almost three times as likely as those aged 21-35 years to have babies with CA, while there was a $52 \%$ increased risk in those older than 35 years, but this was also not statistically significant. Sex, gestational age at birth, maternal parity and the type of gestation (singleton or multiple) were not significantly associated with the occurrence of congenital anomaly at the $5 \%$ level.

Forty-seven $(70.1 \%)$ of the neonates were discharged home after initial treatment; six (9\%) departed against medical advice; seven (10.4\%) were referred and seven (10.4\%) died. Neonates with congenital anomalies were more likely to be referred when compared with only $0.1 \%$ referred among other neonates $(p<0.0001)$. A total of 111 neonates died during the study period, including seven neonates with CA, giving an overall mortality rate of $10.5 \%$. One hundred and nine of the deaths occurred during the neonatal period, giving a neonatal mortality rate of $10.3 \%$. CA accounted for 5.5\% (6/109) of all the neonatal deaths. 
Table 2 Classification of admitted neonates based on congenital anomalies

\begin{tabular}{|c|c|c|}
\hline System & Frequency & $\%$ \\
\hline Nervous system & $n=4$ & \\
\hline Congenital hydrocephalus & 2 & 3.0 \\
\hline Myelomeningocoele & 2 & 3.0 \\
\hline Eye & $n=2$ & 3.0 \\
\hline Cardiovascular system & $n=11$ & \\
\hline Ventricular septal defect & 4 & 6.0 \\
\hline Atrial septal defect & 1 & 1.5 \\
\hline Patent ductus arteriosus & 2 & 3.0 \\
\hline Heart disease- unspecified ${ }^{\mathrm{a}}$ & 4 & 5.0 \\
\hline Orofacial cleft & $n=2$ & \\
\hline Cleft lip \& palate & 2 & 3.0 \\
\hline Digestive system & $n=11$ & \\
\hline Anorectal malformation ${ }^{b}$ & 4 & 6.0 \\
\hline Hirschsprung's disease & 3 & 4.5 \\
\hline Ileal atresia & 1 & 1.5 \\
\hline Malrotation & 1 & 1.5 \\
\hline Biliary atresia & 1 & 1.5 \\
\hline Oesophageal atresia \& trachea-oesophageal fistula & 1 & 1.5 \\
\hline Urinary/Genital & $n=8$ & \\
\hline Hypospadias & 1 & 1.5 \\
\hline Posterior urethral valve & 2 & 3.0 \\
\hline Potter syndrome & 1 & 1.5 \\
\hline Undescended testes & 2 & 3.0 \\
\hline Ambiguous genitalia & 2 & 3.0 \\
\hline Abdominal wall & $n=5$ & \\
\hline Omphalocoele & 5 & 7.5 \\
\hline Limb/Skeletal & $n=8$ & \\
\hline Congenital talipes equinovarus & 6 & 9.0 \\
\hline Genu recurvatum & 1 & 1.5 \\
\hline Polydactyly & 1 & 1.5 \\
\hline Pulmonary & $n=1$ & \\
\hline Laryngomalacia & 1 & 1.5 \\
\hline Other anomalies & $n=5$ & \\
\hline Inguinal hernia & 2 & 3.0 \\
\hline Umbilical hernia $^{c}$ & 1 & 1.5 \\
\hline Congenital subcutaneous nodules & 1 & 1.5 \\
\hline Cystic hygroma & 1 & 1.5 \\
\hline Chromosomal abnormalities & $n=5$ & \\
\hline Down syndromeł & 5 & 7.5 \\
\hline Multiple anomalies & $n=5$ & \\
\hline Cleft palate, undescended testes \& microcephaly & 1 & 1.5 \\
\hline Omphalocoele, VSD \& bilateral inguinoscrotal hernia & 1 & .5 \\
\hline Microcephaly, ventriculomegaly \& VSD & 1 & J. \\
\hline
\end{tabular}

Table 2 Classification of admitted neonates based on congenital anomalies (Continued)

\begin{tabular}{|c|c|c|}
\hline System & Frequency & $\%$ \\
\hline $\begin{array}{l}\text { Spina bifida, congenital talipes } \\
\text { equinovarus \& microcephaly }\end{array}$ & 1 & 1.5 \\
\hline TEF, microphthalmia \& VSD & 1 & 1.5 \\
\hline \multicolumn{3}{|c|}{ 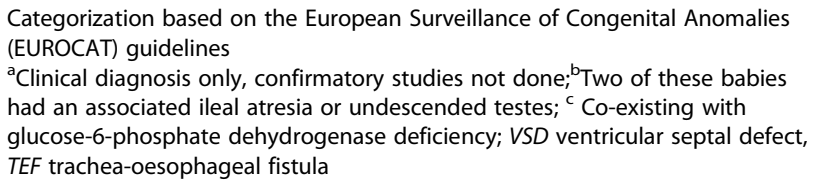 } \\
\hline
\end{tabular}

Prematurity and perinatal asphyxia were the leading cause of neonatal death in this series [Fig. 2].

The neonatal mortality rate (NMR) among patients with CA was 9\% (6/67) as shown in Fig. 2. The NMR was, however, higher among those with prematurity and perinatal asphyxia (Fig. 2). The male sex and the presence of a secondary co-morbidity, such as sepsis were associated with an increased risk of neonatal death but the associations were not statistically significant (Table 4). There was no association between CAs and neonatal death after controlling for gestational age at birth, age at presentation, perinatal asphyxia and the presence of co-morbidity in this present study (Table 4). Older age at presentation and multiple gestation were associated with reduced risk of neonatal death and these were found significant at the $10 \%$ level of significance. Following multivariate Cox regression analysis, only the presence of severe perinatal asphyxia and gestational age at birth independently predicted the risk of neonatal mortality.

\section{Discussion}

Nigeria ranks only second to India in the absolute number of annual neonatal deaths worldwide [4, 27, 28]. CA contribute significantly to this burden, particularly in developing countries [22]. This study was a five-year review of the occurrence, pattern and outcome of CA and its contribution to neonatal mortality in a tertiary health facility in a developing country. The overall prevalence of CA in this study was $6.3 \%$. Our institution receives major referrals from several surrounding communities and this may have accounted for this high yield of anomalies. This demonstrates the magnitude of the burden in developing countries. A high prevalence of CA of $11.1 \%$ among hospital admissions was reported by Adeyemo et al in Ibadan, South-West Nigeria [13]. Our finding was similar to the $6.9 \%$ reported by Bakare et al in Ile-Ife, which is within the same geographical region as our centre [12]. However, similar studies conducted in the South-East and South-South regions of Nigeria have yielded lower prevalence rates of 2.8 and $0.4 \%$, respectively [10, 11]. The lower rate in the South-South region may have been due 
Table 3 Bivariate analysis showing risk factors associated with the occurrence of congenital anomalies

\begin{tabular}{|c|c|c|c|}
\hline Characteristic & Odds ratio & 95\% confidence interval & $p$ value \\
\hline \multicolumn{4}{|l|}{ Sex } \\
\hline \multicolumn{4}{|l|}{ Female (Ref) } \\
\hline Male & 0.84 & $0.51-1.37$ & 0.476 \\
\hline \multicolumn{4}{|c|}{ Birth weight (kg) } \\
\hline$<1.5$ & 0.71 & $0.27-1.85$ & 0.480 \\
\hline $1.5-2.49$ & 1.31 & $0.74-2.32$ & 0.356 \\
\hline \multicolumn{4}{|l|}{$\geq 2.5$ (Ref) } \\
\hline \multicolumn{4}{|c|}{ Gestational age at birth } \\
\hline Preterm & 1.29 & $0.64-2.62$ & 0.478 \\
\hline \multicolumn{4}{|l|}{ Term (Ref) } \\
\hline \multicolumn{4}{|c|}{ Maternal age (years) } \\
\hline$\leq 20$ & 2.69 & $0.63-11.47$ & 0.181 \\
\hline \multicolumn{4}{|l|}{ 21-35 (Ref) } \\
\hline$>35$ & 1.52 & $0.52-4.41$ & 0.446 \\
\hline \multicolumn{4}{|c|}{ Maternal parity } \\
\hline \multicolumn{4}{|l|}{ 1-2 (Ref) } \\
\hline $3-4$ & 1.13 & $0.61-2.12$ & 0.692 \\
\hline$\geq 5$ & 2.30 & $0.92-5.80$ & 0.077 \\
\hline \multicolumn{4}{|c|}{ Type of gestation } \\
\hline \multicolumn{4}{|c|}{ Singleton (Ref) } \\
\hline Multiple & 0.65 & $0.28-1.54$ & 0.326 \\
\hline \multicolumn{4}{|l|}{ Antenatal care } \\
\hline \multicolumn{4}{|l|}{ Yes (Ref) } \\
\hline No & 0.78 & $0.30-2.00$ & 0.606 \\
\hline \multicolumn{4}{|c|}{ Self-medication } \\
\hline Yes & 3.02 & $0.64-14.33$ & 0.163 \\
\hline \multicolumn{4}{|l|}{ No (Ref) } \\
\hline \multicolumn{4}{|c|}{ Use of herbal preparation } \\
\hline Yes & 4.08 & $0.44-37.80$ & 0.215 \\
\hline \multicolumn{4}{|l|}{ No (Ref) } \\
\hline \multicolumn{4}{|c|}{ Maternal febrile illness } \\
\hline Yes & 1.26 & $0.52-3.07$ & 0.615 \\
\hline \multicolumn{4}{|l|}{ No (Ref) } \\
\hline \multicolumn{4}{|c|}{ Folic acid use during first trimester } \\
\hline \multicolumn{4}{|l|}{ Yes (Ref) } \\
\hline No & 0.54 & $0.16-1.83$ & 0.324 \\
\hline
\end{tabular}

to their lower utilization of health facilities for delivery (50.1\%), as shown in the NDHS data [29].

Prevalence studies such as this, help to determine baseline rates and to identify changes over time, which are essential in public health planning of preventive and eradication strategies. This study demonstrates the prevalent nature of birth anomalies. However, we may have significantly under-estimated the actual incidence of these anomalies in the general population. Being a tertiary health facility, complicated cases are more frequently seen, while the uncomplicated cases may have been treated in other peripheral facilities. Anomalies that did not require hospitalization were not captured in this study except where they co-existed with conditions requiring immediate treatment. We also did not include abortions and stillbirths in this study. Previous studies have, however, shown that the incidence of CA is higher among stillbirths and abortuses [7, 17, 30].

The most common anomalies were those of the cardiovascular system, followed by those of the digestive system. This finding was similar to those reported in studies from the United States, Lebanon and the United Kingdom, in which larger cohorts were analyzed $[9,18,31]$. Abudu et al. also reported that the cardiovascular system anomaly was the most common anomaly in autopsies of perinatal deaths in Lagos, Nigeria [30]. The gastrointestinal system was the most common system affected in other studies from Nigeria and North-East India [13, 16, 19, 20]. Some other authors have reported predominance of anomalies of the skeletal and nervous system having focused mainly on externally visible anomalies or self-reports from population-based studies $[3,8,10,11,14,15,22]$.

Related to this, however, is the very significant finding of neonates with the functional anomaly of G6PD deficiency. Almost $5 \%$ of all the neonates had this anomaly, which almost equates the $6.3 \%$ contributed by all structural anomalies in this study. This is in keeping with earlier studies on G6PD in Nigeria, where incidences of 24 and $5 \%$ were reported in males and females, respectively [32]. The high endemicity of malaria in this environment probably plays a significant role as have been previously suggested [33].

The significant association between low birth weight (LBW) and congenital malformations has been well-documented $[8,14,15,17,18]$. Although in the present study, we found that LBW (birth weight between $1.5-2.49 \mathrm{~kg}$ ) was associated with a $30 \%$ higher risk, we did not find this statistically significant. The male sex was associated with a $16 \%$ reduced risk of being born with a CA despite the slight male preponderance among this cohort. There was, however, no significant association between sex and the occurrence of CAs, in contrast to several studies, which have reported male association $[3,8,12,13,16,17,20]$.

It is generally known that maternal lifestyle may predispose to development of CA in their offspring. The consumption of alcohol, cigarette and certain medications are known teratogenic factors $[1,18,21]$. In the present study, smoking and alcohol intake among mothers was negligible and hence, were not significantly associated with these anomalies. The prevalence of smoking is known to be low 


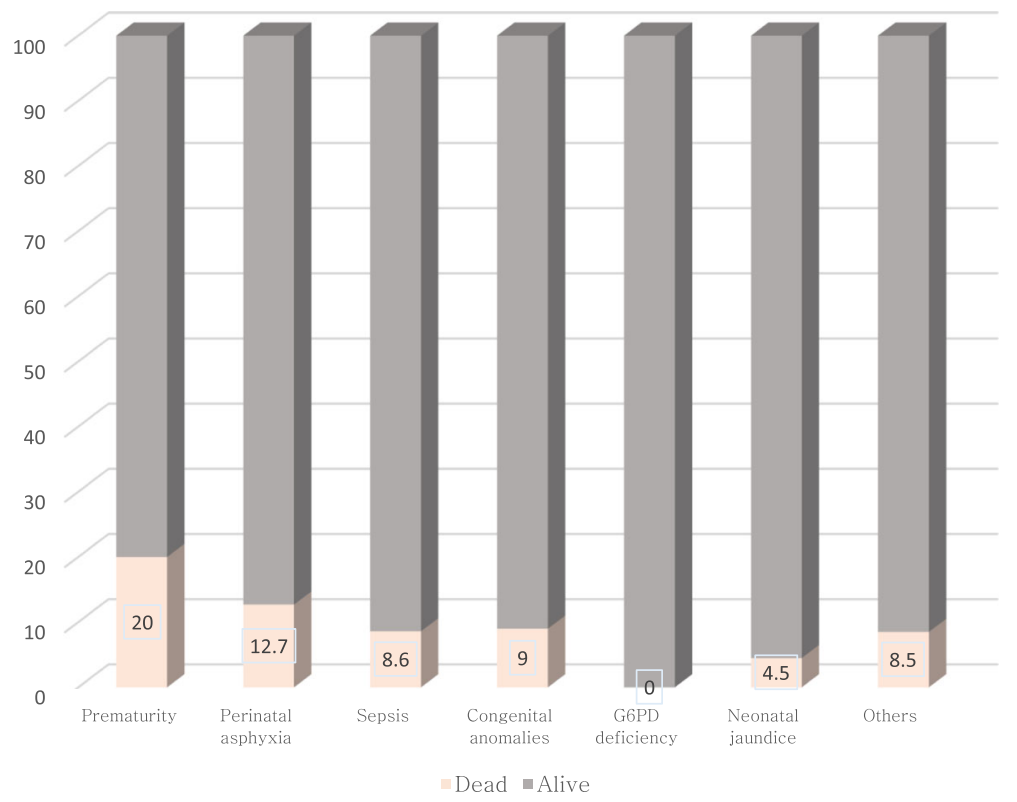

Fig. 2 Chart showing proportion of mortality per disease condition

among women in developing countries [34]. However, the possible effect of paternal smoking and its secondary effect on birth defects were not explored in the present study. We, however, observed that the consumption of herbal preparations and self-medication during pregnancy were associated with three to four times the risk of anomalies as those who do not, but these were not found statistically significant. This may, however, be a point of Public Health interest as the consumption of these uncertified preparations appear prevalent among pregnant women in developing countries.

We did not find any significant association between CA and maternal age, parity, febrile illness, preterm delivery and type of gestation. The mean maternal age was 29.8 $( \pm 5.4)$ years, which falls within the active reproductive years. Many studies have shown an increase in the incidence of birth malformations with increasing maternal age, particularly in mothers older than 35 years [14-16, 21]. The odds of delivering babies with a CA was, however, higher among women younger than 21 years and older than 35 years in the present study. The association of CAs with older maternal age may not have been found significant in our study because of the relatively smaller number of women above 35 years and the low incidence of reported chromosomal anomalies, which are the anomalies often associated with older maternal age [14]. Although, there was an increasing risk of anomalies with increasing parity, this relationship was not found to be statistically significant from our study $(p=0.077)$. Some studies have shown significant association between multiparity and the occurrence of congenital anomalies but the authors did not control for the effect of maternal age as a confounding factor $[8,17]$.
Birth defects have been shown to have significant effect on morbidity and mortality [6]. We assessed the outcome of congenital anomalies and their effect on neonatal mortality, while comparing same with those of neonates admitted for other conditions. We further assessed factors that determined survival among neonates and included the $\mathrm{CA}$ status in the multivariate analysis to determine its independent effect on survival.

A majority of neonates (70\%) with birth defects were discharged home after initial management in our facility. The overall mortality rate among neonates with CA was $10.4 \%$. This was almost comparable to the $16.9 \%$ observed in Ibadan [13]. Mortality from CA accounted for 5.5\% of all neonatal mortalities that occurred during this five-year period. This was higher than that reported by Lawoyin et al in South-West Nigeria, where they investigated the perinatal factors associated with neonatal mortality and found a $3.1 \%$ contribution by congenital abnormalities [35]. The latter study was, however, a community-based study and the authors relied on self-reports and reports from health attendants where medical records were not available. This may have resulted in a lower yield as they also reported that $34.4 \%$ of the neonatal deaths were of unknown cause. Our finding was also similar to the study by Liu et al that reported that congenital anomalies were the fourth leading cause of global neonatal mortality after preterm birth, intra-partum complications and sepsis [5].

The male sex was associated with a higher risk of mortality compared to female neonates. As expected, the presence of co-morbidity increased the risk of neonatal death but did not independently predict the risk. Each additional week of gestation at birth, however, was associated with a 
Table 4 Bivariate and multivariate analysis of 28-day mortality among neonatal admissions

\begin{tabular}{|c|c|c|c|c|c|c|}
\hline Characteristic & Crude HR & $95 \% \mathrm{Cl}$ & $p$ value & Adjusted HR & $95 \% \mathrm{Cl}$ & $p$ value \\
\hline \multicolumn{7}{|l|}{ Congenital anomaly } \\
\hline Yes & 0.89 & $0.39-2.02$ & 0.770 & 0.54 & $0.13-2.23$ & 0.393 \\
\hline \multicolumn{7}{|l|}{ No (Ref) } \\
\hline \multicolumn{7}{|l|}{ Sex } \\
\hline Male & 1.22 & $0.83-1.80$ & 0.308 & & & \\
\hline \multicolumn{7}{|l|}{ Female (Ref) } \\
\hline Gestational age at birth (in weeks) $^{\ddagger}$ & 0.87 & $0.82-0.92$ & $<0.0001^{a}$ & 0.86 & $0.81-0.91$ & $<0.0001^{*}$ \\
\hline Age at presentation (in days) ${ }^{\ddagger}$ & 0.93 & $0.88-0.99$ & $0.015^{\mathrm{a}}$ & 1.05 & $0.97-1.13$ & 0.199 \\
\hline \multicolumn{7}{|l|}{ Birth weight } \\
\hline \multicolumn{7}{|l|}{$<1.5 \mathrm{~kg}$ (Ref) } \\
\hline $1.5-2.49 \mathrm{~kg}$ & 1.04 & $0.48-2.28$ & 0.913 & & & \\
\hline$\geq 2.5$ & 1.26 & $0.62-2.54$ & 0.527 & & & \\
\hline \multicolumn{7}{|l|}{ Type of gestation } \\
\hline \multicolumn{7}{|l|}{ Singleton (Ref) } \\
\hline Multiple & 0.54 & $0.26-1.10$ & $0.090^{a}$ & 0.73 & $0.31-1.72$ & 0.476 \\
\hline \multicolumn{7}{|l|}{ Severe perinatal asphyxia } \\
\hline Yes & 3.97 & $2.66-5.93$ & $<0.0001^{\mathrm{a}}$ & 5.41 & $3.05-9.62$ & $<0.0001^{*}$ \\
\hline \multicolumn{7}{|l|}{ No (Ref) } \\
\hline \multicolumn{7}{|l|}{ Co-morbidity } \\
\hline Yes & 1.40 & $0.89-2.20$ & $0.150^{a}$ & 1.18 & $0.63-2.19$ & 0.603 \\
\hline \multicolumn{7}{|l|}{ No (Ref) } \\
\hline \multicolumn{7}{|l|}{ Maternal parity } \\
\hline \multicolumn{7}{|l|}{ 1-2 (Ref) } \\
\hline $3-4$ & 0.87 & $0.53-1.42$ & 0.575 & & & \\
\hline$\geq 5$ & 0.58 & $0.18-1.85$ & 0.357 & & & \\
\hline \multicolumn{7}{|l|}{ Antenatal care } \\
\hline \multicolumn{7}{|l|}{ Yes (Ref) } \\
\hline No & 0.57 & $0.23-1.41$ & 0.222 & & & \\
\hline
\end{tabular}

*Statistically significant; ${ }^{\ddagger}$ treated as a continuous variable

$14 \%$ reduced risk of neonatal death. Severe perinatal asphyxia increased the risk of neonatal mortality by over five times (Table 4). After eliminating the effect of these other confounders, the CA status did not predict the risk of death.

\section{Limitations}

This was a retrospective review and therefore, had the inherent biases associated with this kind of study. We were unable to retrieve all case files of neonatal admissions; and many of those retrieved, had inadequate information on the perinatal characteristics of the neonates and the maternal risk factors. We could not capture live births that died or were referred without official registration and opening of a case file in our hospital. Furthermore, this was a hospital-based study and may not be generalizable to the general population.

\section{Conclusion}

Congenital anomalies account for $6 \%$ of neonatal hospital admissions in Bowen University Teaching Hospital, Ogbomoso, South-West Nigeria. There is the need to establish a surveillance system for CA in Nigeria to determine their true prevalence, pattern and aetiology in the general population. Because of the high frequency of metabolic disorders in this study, we recommend newborn screening for G6PD deficiency. Efforts should also be made to raise awareness of the occurrence and risk factors of birth defects through health education and advocacy. Improvement in obstetric care, prenatal diagnosis of structural anomalies and early neonatal intensive care is also advocated as these can improve survival in this group of neonates. 


\section{Additional files}

Additional file 1: Spreadsheet of study data in excel format. (XLS $1146 \mathrm{~kb}$ )

Additional file 2: Spreadsheet of study data in .dat format. (DAT $147 \mathrm{~kb}$ )

\section{Abbreviations}

BUTH: Bowen University Teaching Hospital; CA: Congenital anomaly; G6PD: Glucose-6-phosphate dehydrogenase; LMIC: Low- and middle-income country; NDHS: Nigerian demographic and health survey; NMR: Neonatal mortality rate; SPSS: Statistical package for social sciences

\section{Acknowledgements}

We are grateful to all doctors and nurses who managed neonates admitted in the neonatal unit of BUTH. We are also grateful to the staff of the Department of Health Records of BUTH. The authors also acknowledge Drs Olumide Adeleke, Abiola Akinbola, Bisola Ogedengbe, Obafemi Akinyanju, Oluwafemi Oyedeji, Tope Ajao and Soji Otuyemi, who all helped in extracting information from patients' records.

\section{Funding}

No funding was obtained for this study.

\section{Availability of data and materials}

The data sets supporting the conclusions of this article is available within the article as Additional files 1 and 2 .

\section{Authors' contributions}

Conception of research idea and design was by IAA and AEA. AEA conducted the study under the supervision of IAA. AEA conducted the study, analyzed the data and wrote the first draft of the manuscript. IAA reviewed the manuscript. Both read and approved the final draft.

\section{Ethics approval and consent to participate}

Ethical approval was obtained from the Bowen University Teaching Hospita Research Ethics Committee with registration number NHREC/12/04/2012. Being a retrospective review, informed consent was not obtained from individual participants but approval to carry out the study was obtained from the institution Ethics Committee.

\section{Consent for publication}

Not applicable.

\section{Competing interests}

The authors declare that they have no competing interests.

\section{Publisher's Note}

Springer Nature remains neutral with regard to jurisdictional claims in published maps and institutional affiliations.

Received: 16 January 2018 Accepted: 27 March 2019

Published online: 03 April 2019

\section{References}

1. Sadler TW. Birth Defects and Prenatal Diagnosis. In: Langman's medical embryology. 13th ed. Philadelphia: Wolters Kluwer; 2015. p. 126-40.

2. WHO. WHO | Congenital anomalies WHO 2016. http://www.who.int/ mediacentre/factsheets/fs370/en/. Accessed 7 May 2017.

3. Ndibazza J, Lule S, Nampijja M, Mpairwe H, Oduru G, Kiggundu M, et al. A description of congenital anomalies among infants in Entebbe, Uganda. Birt Defects Res A Clin Mol Teratol. 2011:91:857-61.

4. Oestergaard MZ, Inoue M, Yoshida S, Mahanani WR, Gore FM, Cousens S, et al. Neonatal mortality levels for 193 countries in 2009 with trends since 1990: a systematic analysis of Progress, projections, and priorities. PLoS Med. 2011;8:e1001080

5. Liu L, Oza S, Hogan D, Perin J, Rudan I, Lawn JE, et al. Global, regional, and national causes of child mortality in 2000-13, with projections to inform post2015 priorities: an updated systematic analysis. Lancet. 2015;385:430-40.
6. Sitkin NA, Ozgediz D, Donkor P, Farmer DL. Congenital anomalies in lowand middle-income countries: the unborn child of global surgery. World J Surg. 2015;39:36-40

7. Kumar P. Dysmorphology. In: Kumar P, Burton B, editors. Congenital malformations. 1st edition. Blacklick. USA: McGraw-Hill Professional Publishing; 2008. p. 3-11.

8. Sarkar S, Patra C, Dasgupta MK, Nayek K, Karmakar PR. Prevalence of congenital anomalies in neonates and associated risk factors in a tertiary care hospital in eastern India. J Clin Neonatol. 2013;2:131.

9. Egbe A, Uppu S, Lee S, Stroustrup A, Ho D, Srivastava S. Congenital malformations in the newborn population: a population study and analysis of the effect of sex and prematurity. Pediatr Neonatol. 2015;56:25-30.

10. Ekanem TB, Okon DE, Akpantah AO, Mesembe OE, Eluwa MA, Ekong MB. Prevalence of congenital malformations in Cross River and Akwa Ibom states of Nigeria from 1980-2003. Congenit Anom. 2008:48:167-70.

11. Obu HA, Chinawa JM, Uleanya ND, Adimora GN, Obi IE. Congenital malformations among newborns admitted in the neonatal unit of a tertiary hospital in Enugu, south-East Nigeria - a retrospective study. BMC Res Notes. 2012;5:177.

12. Bakare TIB, Sowande OA, Adejuyigbe OO, Chinda JY, Usang UE. Epidemiology of external birth defects in neonates in south western Nigeria. Afr J Paediatr Surg. 2009:6:28.

13. Adeyemo AA, Gbadegesin RA, Omotade OO. Major congenital malformations among neonatal referrals to a Nigerian University teaching hospital. East Afr Med J. 1997;74:699-701.

14. Chen B-Y, Hwang B-F, Guo Y-L. Epidemiology of congenital anomalies in a population-based Birth registry in Taiwan, 2002. J Formos Med Assoc. 2009; 108:460-8.

15. Cosme HW, Lima LS, Barbosa LG. Prevalence of congenital anomalies and their associated factors in newborns in the city of Sao Paulo from 2010 to 2014. Rev Paul Pediatr Orgao Of Soc Pediatr Sao Paulo. 2017;35:33-8.

16. Chowdhury P, Devi RP, Singh LB, Thakare AS, Tamang ZD, Debroy S, et al. Clinical study on congenital malformations at Birth in a tertiary leve Hospital in North-East India. IOSR J Dent Med Sci IOSR-JDMS. 2017;1:24-7.

17. Taksande A, Vilhekar K, Chaturvedi P, Jain M. Congenital malformations at birth in Central India: a rural medical college hospital based data. Indian J Hum Genet. 2010;16:159.

18. Francine $\mathrm{R}$, Pascale $\mathrm{S}$, Aline $\mathrm{H}$. Congenital anomalies: prevalence and risk factors. Univers J Public Health. 2014:2:58-63.

19. Ekwere EO, McNeil R, Agim B, Jeminiwa B, Oni O, Pam S. A retrospective study of congenital anomalies presented at tertiary health facilities in Jos, Nigeria. Journal of Physics: Conference Series (JPCS). 2011; http://irepos.unijos.edu.ng/jspui/handle/123456789/1229. Accessed 9 Aug 2017.

20. Lawal T, Adeleye AO, Ayede Al, Ogundoyin OO, Olulana D, Olusanya A, et al. Congenital paediatric surgical cases in Ibadan: patterns and associated malformations. Afr J Med Med Sci. 2017;46:49-55.

21. Căpătînă D, Cozaru GC. Risk factors associated with congenital anomalies in children. ARS Medica Tomitana. 2015;21:105-11.

22. Sachdeva S, Nanda S, Bhalla K, Sachdeva R. Gross congenital malformation at birth in a government hospital. Indian J Public Health. 2014;58:54.

23. Macintosh MC, Fleming KM, Bailey JA, Doyle P, Modder J, Acolet D, et al. Perinatal mortality and congenital anomalies in babies of women with type 1 or type 2 diabetes in England, Wales, and Northern Ireland: population based study. BMJ. 2006;333:177.

24. Malcoe LH, Shaw GM, Lammer EJ, Herman AA. The effect of congenital anomalies on mortality risk in white and black infants. Am J Public Health. 1999:89:887-92.

25. Lawal TA, Yusuf B, Fatiregun AA. Knowledge of birth defects among nursing mothers in a developing country. Afr Health Sci. 2015;15:180-7.

26. EUROCAT. http://www.eurocat-network.eu/aboutus/datacollection/ guidelinesforregistration/malformationcodingguides. Accessed 19 Jul 2018.

27. Akinyemi JO, Bamgboye EA, Ayeni O. Trends in neonatal mortality in Nigeria and effects of bio-demographic and maternal characteristics. BMC Pediatr. 2015;15:36.

28. Ezeh OK, Agho KE, Dibley MJ, Hall J, Page AN. Determinants of neonata mortality in Nigeria: evidence from the 2008 demographic and health survey, BMC Public Health, 2014:14:521.

29. National Population Commission (NPC) [Nigeria] and ICF International. Reprodutive health. In: Nigeria Demographic and Health Survey 2013. Abuja and Rockville: NPC and ICF International; 2014. p. 127-54. 
30. Abudu OO, Uguru V, Olude O. Contribution of congenital malformation to perinatal mortality in Lagos, Nigeria. Int J Gynecol Obstet. 1988;27:63-7.

31. Tennant PW, Pearce MS, Bythell M, Rankin J. 20-year survival of children born with congenital anomalies: a population-based study. Lancet. 2010; 375:649-56.

32. Ademowo OG, Falusi AG. Molecular epidemiology and activity of erythrocyte G6PD variants in a homogenous Nigerian population. East Afr Med J. 2002;79:42-5.

33. Ouattara AK, Bisseye C, Bazie BVJTE, Diarra B, Compaore TR, Djigma F, et al. Glucose-6-phosphate dehydrogenase (G6PD) deficiency is associated with asymptomatic malaria in a rural community in Burkina Faso. Asian Pac J Trop Biomed. 2014;4:655-8.

34. Ng M, Freeman MK, Fleming TD, Robinson M, Dwyer-Lindgren L, Thomson $B$, et al. Smoking prevalence and cigarette consumption in 187 countries, 1980-2012. Jama. 2014:311:183-92.

35. Lawoyin TO, Onadeko MO, Asekun-Olarinmoye EO. Neonatal mortality and perinatal risk factors in rural southwestern Nigeria: a community-based prospective study. West Afr J Med. 2010;29:19-23.

Ready to submit your research? Choose BMC and benefit from:

- fast, convenient online submission

- thorough peer review by experienced researchers in your field

- rapid publication on acceptance

- support for research data, including large and complex data types

- gold Open Access which fosters wider collaboration and increased citations

- maximum visibility for your research: over $100 \mathrm{M}$ website views per year

At $\mathrm{BMC}$, research is always in progress.

Learn more biomedcentral.com/submissions 